\title{
Adherence to a Mediterranean diet and plasma fatty acids: data from the Bordeaux sample of the Three-City study
}

\author{
Catherine Féart ${ }^{1,2 *}$, Marion J. M. Torrès ${ }^{1,2}$, Cécilia Samieri ${ }^{1,2}$, Marthe-Aline Jutand ${ }^{1,2}$, \\ Evelyne Peuchant ${ }^{2,3,4}$, Artemis P. Simopoulos ${ }^{5}$ and Pascale Barberger-Gateau ${ }^{1,2}$ \\ ${ }^{1}$ Equipe Epidémiologie de la Nutrition et des Comportements Alimentaires, INSERM, U897, Université Victor Ségalen \\ Bordeaux 2, ISPED Case 11, 146 rue Léo-Saignat, F-33076 Bordeaux Cedex, France \\ ${ }^{2}$ Université Bordeaux 2, Bordeaux F-33076, France \\ ${ }^{3}$ INSERM, U876, Bordeaux F-33076, France \\ ${ }^{4}$ CHU de Bordeaux, Hôpital Saint-André, Service de Biochimie, Bordeaux F-33075, France \\ ${ }^{5}$ The Center for Genetics, Nutrition and Health, 2001 S Street, NW, Suite 530, Washington, DC 20009, USA
}

(Received 15 September 2010 - Revised 1 December 2010 - Accepted 10 December 2010 - First published online 8 February 2011)

\section{Abstract}

Higher adherence to a Mediterranean diet (MeDi) and n-3 PUFA may both contribute to decreased dementia risk, but the association between MeDi adherence and lipid status is unclear. The aim of the present study was to analyse the relationship between plasma fatty acids and MeDi adherence in French elderly community dwellers. The study population (mean age 75.9 years) consisted of 1050 subjects from Bordeaux (France) included in the Three-City cohort. Adherence to the MeDi (scored as 0-9) was computed from a FFQ and $24 \mathrm{~h}$ recall. The proportion of each plasma fatty acid was determined. Cross-sectional analysis of the association between plasma fatty acids and MeDi adherence was performed by multi-linear regression. After adjusting for age, sex, energy intake, physical activity, smoking status, BMI, plasma TAG and apoE- $\varepsilon 4$ genotype, plasma palmitoleic acid was significantly inversely associated with MeDi adherence, whereas plasma DHA, the EPA + DHA index and total $n$-3 PUFA were positively associated with MeDi adherence. The $n$ - $6: n-3$ PUFA, arachidonic acid (AA):EPA, AA:DHA and AA:(EPA + DHA) ratios were significantly inversely associated with MeDi adherence. Plasma EPA was positively associated with MeDi adherence only in apoE- $\varepsilon 4$ non-carriers. There was no association between MeDi adherence and SFA and total MUFA. The present results suggest that the protective effect of the MeDi on cognitive functions might be mediated by higher plasma DHA and lower $n-6: n-3$ PUFA ratios.

Key words: Mediterranean diet: Plasma fatty acids: Older persons

The Mediterranean diet (MeDi) is a dietary pattern first described from observational studies which have reported low all-cause and CHD death rates in cohorts of the Mediterranean basin, with olive oil as the main fat ${ }^{(1)}$. There is no single MeDi but several definitions, since populations living in countries bordering the Mediterranean Sea have various dietary habits ${ }^{(2,3)}$. Nevertheless, a high consumption of vegetables, legumes, fruits and cereals, a moderate-to-high intake of fish, a high MUFA:SFA ratio and a low intake of dairy products and meat, concomitant with a low-to-moderate intake of wine, define the common line of this dietary pattern $^{(4-6)}$. The Mediterranean-style diet seems an optimal dietary strategy for health since a greater MeDi adherence, as evaluated by the MeDi score, has been associated with longer survival, reduced risk for cardiovascular mortality and cancer incidence and mortality ${ }^{(7-9)}$. It has been hypothesised that $n-3$ PUFA and a balanced $n-6: n-3$ PUFA ratio associated with a high intake of antioxidants in the MeDi could be important determinants in influencing $\mathrm{CVD}^{(2)}$. Moreover, recent studies, the Washington Heights-Inwood Columbia Aging Project in the USA ${ }^{(10)}$ and the Three-City (3C) study in France ${ }^{(11)}$, have evidenced a decreased risk of Alzheimer's disease and a slower cognitive decline with greater MeDi adherence $^{(12)}$. As for CVD protection, the MeDi combines several foods and nutrients which might protect against cognitive dysfunction or dementia such as fish, as the main provider of long-chain n-3 PUFA, olive oil, as the main source of MUFA, vitamins $\mathrm{B}_{12}$, folate, and antioxidants (vitamin $\mathrm{E}$, carotenoids and flavonoids $)^{(13-20)}$. In particular, there is a growing interest in the putative protective effects of fish and long-chain $n$-3 PUFA, notably DHA (22:6n-3), against age-related cognitive disorders $^{(21-23)}$. However, computation of the MeDi score is

Abbreviations: 3C, Three-City; AA, arachidonic acid; MeDi, Mediterranean diet.

* Corresponding author: C. Féart, fax +33 5575714 86, email catherine.Feart@isped.u-bordeaux2.fr 
based on dietary data, which may not accurately reflect the bioavailability of nutrients ${ }^{(5)}$. Nutritional biomarkers are necessary to understand the mechanisms underlying the link between MeDi adherence and health outcomes. In particular, $n-3$ PUFA biomarkers are more precise risk predictors than dietary intake estimates ${ }^{(24)}$. Plasma fatty acids have largely been used to validate nutrient intake but less frequently to characterise food patterns. Hence, data on the association between MeDi adherence and fatty acid status are scarce. A single observational study conducted in Greece has reported an association between MeDi adherence and plasma fatty acids in adults ${ }^{(25)}$. Nevertheless, several dietary patterns corresponding to a similar MeDi adherence may differ in other countries not close to the Mediterranean Sea ${ }^{(3)}$.

The present study examined whether spontaneous MeDi adherence was associated with plasma fatty acids in a large population-based sample of older people in France, included in the $3 \mathrm{C}$ study, where an association was evidenced between MeDi adherence and slower cognitive decline.

\section{Subjects and methods}

\section{Participants}

The data come from the Bordeaux sample of the $3 \mathrm{C}$ study, a prospective cohort study of vascular risk factors of dementia whose methodology has been described in detail elsewhere ${ }^{(26)}$. The present study was conducted according to the guidelines laid down in the Declaration of Helsinki. The protocol of the 3C study was approved by the Consultative Committee for the Protection of Persons participating in Biomedical Research of the Kremlin-Bicêtre University Hospital (Paris, France). All participants signed a written consent. A sample of 2104 community dwellers aged 65 years and above was selected in 1999-2000 from the electoral rolls of Bordeaux. The baseline data collection included sociodemographic information, lifestyle, symptoms and complaints, medical history of CVD and stroke, blood pressure, past and present consumption of tobacco, alcohol and drug use, anthropometric data, neuropsychological testing, and blood sampling. The data were completed by a comprehensive dietary survey in the Bordeaux centre in 2001-2002. Bordeaux is also the only study centre where plasma fatty acid determination was performed.

\section{Plasma lipid and fatty acid analysis}

Fasting blood samples were obtained simultaneously from the baseline data collection in Bordeaux ( $n$ 1416). Blood was collected in heparinised vacutainers and centrifuged at $1000 \mathrm{~g}$ for $10 \mathrm{~min}$. Plasma samples were divided into aliquots and frozen immediately at $-80^{\circ} \mathrm{C}$. After 36 months of storage at $-80^{\circ} \mathrm{C}$, aliquots were unfrozen for plasma fatty acid measurements, which were performed immediately. Total lipids were extracted from the plasma with $5 \mathrm{ml}$ of hexane-isopropanol $(3: 2, \mathrm{v} / \mathrm{v})$. Plasma fatty acid composition was determined from $2 \mathrm{ml}$ of the lipid extract after transformation into isopropyl esters ${ }^{(27)}$. Separation of isopropyl esters was done on a gas chromatograph (Trace; Thermoelectron, Courtaboeuf Cedex, France) using a $25 \mathrm{~m}$ Carbowax capillary column (internal diameter $0.32 \mathrm{~mm}$ ). Column conditions were $180^{\circ} \mathrm{C}$ for $5 \mathrm{~min}$, increasing by $7.5^{\circ} \mathrm{C} / \mathrm{min}$ to $220^{\circ} \mathrm{C}$ for $30 \mathrm{~min}$. The injector was at $60^{\circ} \mathrm{C}$, and the flame ionisation detector was at $250^{\circ} \mathrm{C}$. Helium was used as the carrier gas (flow rate $2 \mathrm{ml} / \mathrm{min}$ ). The peaks were identified by comparison with reference fatty acid esters (Sigma Chemical Company, Saint-Quentin Fallavier, France), and peak areas were measured with an automatic integrator (DP700; Fisons Instruments, Arcueil Cedex, France). The results of each fatty acid were expressed as percentage of total fatty acids. Total $n-6$ PUFA was the sum of linoleic acid (18:2n-6), $\gamma$-linolenic acid (18:3n-6) and arachidonic acid (AA, $20: 4 n-6$ ) proportions, and total $n-3$ PUFA was the sum of $\alpha$-linolenic acid (18:3n-3), EPA (20:5n-3), docosapentaenoic acid (22:5n-3) and DHA (22:6n-3) proportions. The sum of plasma $20: 5 n-3$ and $22: 6 n-3$ proportions was used as a proxy of the erythrocyte $n-3$ index ${ }^{(24)}$. The MUFA:SFA, $n-6: n-3$ PUFA, linoleic acid: $\alpha$-linolenic acid, AA:EPA, AA:DHA and AA:(EPA + DHA) ratios were calculated. Fatty acid composition was available only in the plasma.

\section{Dietary assessment and Mediterranean diet score}

In Bordeaux, participants ( $n$ 1660) were visited at home by a specifically trained dietitian who administered a FFQ and a $24 \mathrm{~h}$ dietary recall ${ }^{(28,29)}$. The $24 \mathrm{~h}$ recall was used to estimate nutrient intake in $\mathrm{g} / \mathrm{d}$, total energy intake in $\mathrm{kJ} / \mathrm{d}$ and to compute the dietary MUFA:SFA ratio. Based on the FFQ, usual frequency of consumption in the previous year of forty categories of foods and beverages for each of the three main meals and three between-meal snacks was recorded in eleven classes. The food items were converted into number of servings per week and then aggregated into twenty food and beverage groups as described earlier ${ }^{(29)}$. We computed mean number of servings per week for the food groups considered to be part of the MeDi: vegetables, fruits, legumes, cereals including bread, pasta and rice (whole and refined grains), fish, meat, dairy products and alcohol. The MeDi score was computed as follows: a value of 0 or 1 was assigned to each food group using sex-specific medians of the population as cut-offs (see e-Table 2 of the supplementary material, available online at http://www.journals.cambridge.org/bjn). For beneficial components (vegetables, fruits, legumes, cereals and fish), individuals whose consumption was below the median were assigned a value of 0 , compared with 1 for the others. For components presumed to be detrimental (meat and dairy products), individuals whose consumption was below the median were assigned 1 , compared with 0 for the others. For alcohol, 1 point was given to mild-to-moderate consumers. The second quartile of the distribution of total alcohol was chosen as the cut-off in men and women separately. A score of 1 point was attributed for men if consumption was within 6-14 glasses/week (8.6-20 g/d) and for women if consumption was within 1-4 glasses/week (1.4$5.7 \mathrm{~g} / \mathrm{d}$ ). For the dietary MUFA:SFA ratio, ratios below the sex-specific median were given a value of 0 , compared with 1 for those above the median. The MeDi score was generated 
by adding the scores ( 0 or 1 point) for each food category for each participant. Thus, the MeDi score could range from 0 to 9, with higher scores indicating greater MeDi adherence ${ }^{(5)}$.

\section{Other variables}

Sociodemographic information recorded at baseline included age, sex, education, income and marital status. Height (m) and weight $(\mathrm{kg})$ were measured by the interviewers at baseline. BMI was computed as the weight:height ${ }^{2}$ ratio. Biological data assessed at the same time were used to obtain information on the presence of chronic conditions including hypertension (blood pressure $\geq 140 / 90 \mathrm{mmHg}$ or treated), diabetes (fasting blood glucose $\geq 7.2 \mathrm{mmol} / \mathrm{l}$ or treated) and hypercholesterolaemia (total serum cholesterol $\geq 6.2 \mathrm{mmol} / \mathrm{l}$ ). The baseline blood sampling also included fasting plasma TAG measurement. Plasma TAG was analysed enzymatically using a multiparameter automated analyser (LX20; Coulter-Beckman, Paris, France) and used as a proxy of overall lipid status in our analysis. Smoking status and history of CVD or cerebrovascular disease were also considered as vascular risk factors ${ }^{(26)}$. Genotyping was performed at the Lille Genopole (France), and apoE genotype was considered dichotomously: presence of at least one $\varepsilon 4$ allele $v$. no $\varepsilon 4$ allele ${ }^{(30)}$. The practice of physical exercise was assessed on a self-administered questionnaire ${ }^{(28)}$.

The diagnosis of dementia was based on a two-step procedure following the administration of the battery of neuropsychological tests ${ }^{(26)}$. At each wave of the $3 \mathrm{C}$ study, the participants who were suspected of dementia on the basis of their present neuropsychological performances and declined relatively to a previous examination were examined by a neurologist. Then, an independent committee of neurologists reviewed all potential cases of dementia and analysed in depth the medical history of each participant to obtain a consensus on the diagnosis and aetiology according to the criteria of the Diagnostic and Statistical Manual of Mental Disorders, fourth edition. In total, fifty-five subjects with dementia were identified and then excluded.

\section{Statistical analyses}

All statistical analyses were performed with the SAS Statistical package (version 9.1; SAS Institute, Cary, NC, USA). Participants were classified according to categories of the MeDi score. The MeDi categories (low, scores 0-3; middle, scores 4-5; high, scores 6-9) were defined so as to be nutritionally relevant, close to tertiles of the distribution of the MeDi score in our sample and similar to those used in previous studies ${ }^{(5,10,11)}$. Demographic and clinical characteristics were compared between categories of the MeDi score using $\chi^{2}$ statistics for class variables and ANOVA, followed by $2 \times 2$ comparison post hoc tests for continuous variables (accepted significance at $P<0.05)$. The Pearson correlation coefficient was used to investigate the association between each plasma fatty acid or each fatty acid ratio and MeDi adherence as the continuous variable (scores 0-9). The association between each plasma fatty acid and each fatty acid ratio and MeDi adherence as the categorical variable was assessed using ANOVA. For each plasma fatty acid percentage or ratio, which was separately associated with MeDi adherence at $P<0.20$ in Pearson's correlation analyses, multivariate linear regression was performed. Analyses of the association between plasma fatty acid percentages or ratios (entered into separate models as continuous variables) and MeDi adherence as the continuous variable were subsequently adjusted for age (continuous), sex, energy intake and physical activity in model 1 , and for smoking status, BMI, apoE genotype and plasma TAG in addition to the previous covariates in model 2 . The normality of residuals of each dependent variable (i.e. plasma fatty acid percentages or ratios) has been confirmed, and all hypotheses of each multivariate linear regression model have been satisfied in all statistical models. Statistical interactions between the MeDi score and apoE genotype were tested, and when a statistically significant interaction at $P<0.05$ was detected, stratified analyses based on apoE genotype were conducted.

\section{Results}

Among the 1416 subjects with plasma fatty acid assessment, 1105 had a full dietary assessment. We excluded fifty-five participants with dementia. Thus, the study sample consisted of 1050 individuals, aged 75.9 years on average (range 67.894.9). Participants not included ( $n$ 366) in the present study were older, less educated and with lower income, had more often a medical history of stroke and were more often exsmokers. They were more often $\varepsilon$ 4-allele carriers (24 v. 18.6\%, $P=0 \cdot 02$ ). Moreover, subjects not included had a different plasma fatty acid profile. They had higher mean plasma MUFA and 18:1n-9 proportions and significant higher AA:EPA, AA:(EPA + DHA) and total $n-6: n-3$ PUFA ratios than the included subjects (see e-Table 1 of the supplementary material, available online at http://www.journals.cambridge. org/bjn). Participants not included in the study had lower mean plasma total $n-3$ PUFA, $20: 5 n-3$ and EPA + DHA index than the included participants. There were no significant differences for the other plasma fatty acids or ratios $(P>0.05)$ (see e-Table 1 of the supplementary material, available online at http://www.journals.cambridge.org/bjn).

The median of consumption of cereals was 23.0 servings per week for women $v .24 \cdot 0$ for men. The medians of consumption of dairy products, meat, vegetables, fruits, legumes and fish and of the MUFA:SFA ratio were very similar in men and women (see e-Table 2 of the supplementary material, available online at http://www.journals.cambridge.org/bjn). The MeDi score ranged from 0 to 8 with less than $4 \%$ of the total population in the extreme values ( 0 or 8 ). Of all the participants, $29 \%$ had a low MeDi score (low category, scored as $0-3), 42 \%$ had an MeDi score of 4 or 5 (middle category) and $29 \%$ were considered high MeDi adherents (scored as 6-9). The mean MeDi score was 4.40 (SD 1.70, median 4.0), and its distribution was normal.

As expected, greater MeDi adherence was characterised by higher intake of vegetables, fruits, legumes, cereals and fish and by lower intake of meat and dairy products (Table 1 ). 
Table 1. Number of servings per week for individual food categories, proportion of mild-to-moderate alcohol consumers and ratio of daily intake of MUFA:SFA by categories of the Mediterranean diet (MeDi) score among older persons living in Bordeaux, the Three-City study (2001-2002)

(Mean values and standard deviations, $n$ 1050)

\begin{tabular}{|c|c|c|c|c|c|c|}
\hline \multirow[b]{2}{*}{ Food categories* } & \multicolumn{2}{|c|}{$\begin{array}{c}\text { Low category } \\
\text { (MeDi score 0-3) } \\
(n 310)\end{array}$} & \multicolumn{2}{|c|}{$\begin{array}{c}\text { Middle category } \\
\text { (MeDi score 4-5) } \\
(n \text { 438) }\end{array}$} & \multicolumn{2}{|c|}{$\begin{array}{l}\text { High category } \\
\text { (MeDi score 6-9) } \\
\text { (n 302) }\end{array}$} \\
\hline & Mean & SD & Mean & SD & Mean & SD \\
\hline \multicolumn{7}{|l|}{ Servings/week } \\
\hline Dairy products & $18 \cdot 7$ & $7 \cdot 7$ & $15 \cdot 5$ & $7 \cdot 0$ & $14 \cdot 3$ & $6 \cdot 6$ \\
\hline Meat & $5 \cdot 7$ & $2 \cdot 6$ & 4.8 & $2 \cdot 4$ & $4 \cdot 1$ & $2 \cdot 0$ \\
\hline Vegetables & $15 \cdot 7$ & $6 \cdot 5$ & 19.5 & $7 \cdot 1$ & $22 \cdot 9$ & $6 \cdot 8$ \\
\hline Fruits & $10 \cdot 5$ & $6 \cdot 2$ & $13 \cdot 8$ & $6 \cdot 6$ & $16 \cdot 2$ & $6 \cdot 3$ \\
\hline Legumes & 0.5 & 0.8 & 0.6 & 0.6 & 0.8 & 0.7 \\
\hline Cereals $\dagger$ & $20 \cdot 2$ & $6 \cdot 4$ & $21 \cdot 8$ & 5.9 & $24 \cdot 0$ & $5 \cdot 8$ \\
\hline Fish & $2 \cdot 0$ & 1.4 & $2 \cdot 9$ & $1 \cdot 7$ & 3.7 & 1.6 \\
\hline Mild-to-moderate alcohol $(\%)$ & \multicolumn{2}{|c|}{$13 \cdot 6$} & \multicolumn{2}{|c|}{23.5} & \multicolumn{2}{|c|}{44.7} \\
\hline MUFA:SFA ratio $(\mathrm{g} / \mathrm{d})$ & 0.76 & 0.24 & 0.89 & 0.36 & 1.00 & 0.32 \\
\hline
\end{tabular}

MeDi adherence was not significantly associated with demographic or clinical characteristics (Table 2). Greater MeDi adherence was only associated with being married and never smoking status with borderline significance $(P<0 \cdot 10)$.

Plasma fatty acids were mainly composed of SFA (more than $41 \%$ of total plasma fatty acids), followed by PUFA (36.3\% on average), mainly $n-6$ PUFA, and MUFA (22.6\% on average (Table 3 ).

Pearson's correlation coefficients revealed a significant positive relationship between the MeDi score and plasma 22:6n-3, plasma EPA + DHA index and total $n$-3 PUFA (Table 3). Inverse correlations between the MeDi score and plasma total MUFA and 16:1n-7 were observed. There was no association between the MeDi score and plasma SFA or any of the $n$-6 PUFA. The directions of the correlations between the MeDi score and several plasma fatty acid ratios (n-6:n-3 PUFA, AA:EPA, AA:DHA and AA:(EPA + DHA)) were in full agreement with the positive association between n-3 PUFA and the MeDi score.

The associations between plasma fatty acids and fatty acid ratios and the MeDi score as a categorical variable are shown in Table 4. The percentages of each fatty acid in plasma did not differ across MeDi categories, except for $16: 1 n-7,22: 6 n-3$, EPA + DHA index and total $n-3$ PUFA. Individuals in the high MeDi category had a lower mean plasma $16: 1 n-7$ and higher mean plasma $22: 6 n-3, \mathrm{EPA}+\mathrm{DHA}$ index and total $n$-3 PUFA than those in the lowest category. Moreover, mean AA:EPA, AA:DHA, AA:(EPA + DHA) and total $n$-6:n-3 PUFA ratios significantly decreased with increasing MeDi adherence. There was no association between the MeDi, as a categorical variable and plasma total SFA, total PUFA and $n$ - 6 PUFA or the MUFA:SFA and linoleic acid: $\alpha$-linolenic acid ratios.
For each plasma fatty acid percentage or ratio, which was separately associated with MeDi adherence at $P<0 \cdot 20$ in Pearson's correlation analyses, multivariate linear regression was performed (Table 5). In models adjusted for age, sex, energy intake, physical activity, smoking status, BMI, plasma TAG and apoE genotype, plasma $16: 1 n-7$ was significantly inversely associated with the MeDi score. The MeDi score was positively associated with plasma $22: 6 n-3$, EPA + DHA index and plasma total $n-3$ PUFA. However, when considering the association between plasma $20: 5 n-3$ and the MeDi score as continuous data, a significant statistical interaction between the MeDi score and apoE genotype was observed $(P=0.03)$. Stratified analyses were therefore conducted based on the apoE- $\varepsilon 4$ status (Table 5). Plasma 20:5n-3 was significantly positively associated with the MeDi score only in apoE- $\varepsilon 4$ non-carriers. Finally, the total $n-6: n-3$ PUFA, AA:EPA, AA:DHA and AA:(EPA + DHA) ratios significantly decreased when MeDi adherence increased in fully adjusted models (Table 5). No other significant interaction between the MeDi score and apoE- $\varepsilon 4$ genotype was observed.

\section{Discussion}

The present study shows a positive association between MeDi adherence and plasma 22:6n-3, EPA + DHA index and plasma total $n$-3 PUFA, and, conversely, an inverse association between MeDi adherence and plasma palmitoleic acid, and several n-6:n-3 PUFA ratios. Plasma $20: 5 n-3$ was significantly positively associated with MeDi adherence only in apoE- $\varepsilon 4$ non-carriers. These associations were independent of energy intake, BMI, physical activity and plasma TAG

To date, few studies have investigated the association between MeDi adherence and plasma fatty acids, and interestingly, the present results are almost fully consistent with those previous studies. In 374 adults enrolled in the ATTICA study 
Table 2. Demographic, clinical and dietary characteristics by categories of the Mediterranean diet (MeDi) score among older persons living in Bordeaux, the Three-City study (2001-2002)

(Mean values, standard deviations, number of subjects and percentages, $n$ 1050)

\begin{tabular}{|c|c|c|c|c|c|c|c|}
\hline & \multicolumn{2}{|c|}{$\begin{array}{l}\text { Low category } \\
\text { (MeDi score } \\
0-3)(n 310)\end{array}$} & \multicolumn{2}{|c|}{$\begin{array}{l}\text { Middle category } \\
\text { (MeDi score } \\
4-5)(n 438)\end{array}$} & \multicolumn{2}{|c|}{$\begin{array}{l}\text { High category } \\
\text { (MeDi score } \\
6-9)(n 302)\end{array}$} & \multirow[b]{2}{*}{$P^{*}$} \\
\hline & $n$ & $\%$ & $n$ & $\%$ & $n$ & $\%$ & \\
\hline \multicolumn{8}{|l|}{ Demographic characteristics } \\
\hline Age (years) & 310 & & 438 & & 302 & & 0.83 \\
\hline Mean & \multicolumn{2}{|c|}{$\begin{array}{c}75.7 \\
4.9\end{array}$} & \multicolumn{2}{|c|}{$\begin{array}{c}76 \cdot 0 \\
5.0\end{array}$} & \multicolumn{2}{|c|}{$\begin{array}{c}75.9 \\
4.5\end{array}$} & \\
\hline Women & 194 & $62 \cdot 6$ & 253 & $57 \cdot 8$ & 190 & $62 \cdot 9$ & 0.26 \\
\hline Education & & & & & & & 0.34 \\
\hline No or primary school & 102 & $32 \cdot 0$ & 135 & 31.0 & 91 & $30 \cdot 3$ & \\
\hline Secondary & 92 & $29 \cdot 7$ & 119 & $27 \cdot 3$ & 78 & $26 \cdot 0$ & \\
\hline High school & 72 & $23 \cdot 2$ & 92 & $21 \cdot 1$ & 67 & $22 \cdot 3$ & \\
\hline University & 44 & 14.2 & 90 & 20.6 & 64 & $21 \cdot 3$ & \\
\hline Monthly income $(€)$ & & & & & & & 0.54 \\
\hline Refused to answer & 14 & 4.6 & 23 & $5 \cdot 3$ & 14 & 4.7 & \\
\hline$<750$ & 25 & $8 \cdot 2$ & 26 & $6 \cdot 0$ & 22 & $7 \cdot 3$ & \\
\hline $750-1500$ & 113 & 36.9 & 140 & $32 \cdot 2$ & 91 & $30 \cdot 3$ & \\
\hline $1500-2250$ & 73 & 23.9 & 112 & $25 \cdot 8$ & 71 & 23.7 & \\
\hline$>2250$ & 81 & $26 \cdot 5$ & 134 & $30 \cdot 8$ & 102 & $34 \cdot 0$ & \\
\hline Marital status & & & & & & & 0.09 \\
\hline Married & 173 & $55 \cdot 8$ & 255 & $58 \cdot 2$ & 195 & $65 \cdot 6$ & \\
\hline Divorced/separated & 22 & $7 \cdot 1$ & 31 & $7 \cdot 1$ & 23 & 7.6 & \\
\hline Widowed & 101 & $32 \cdot 6$ & 122 & $27 \cdot 8$ & 61 & $20 \cdot 2$ & \\
\hline Single & 13 & 4.2 & 28 & 6.4 & 22 & $7 \cdot 3$ & \\
\hline Practice of physical exercise & & & & & & & 0.18 \\
\hline No & 193 & $62 \cdot 2$ & 249 & $56 \cdot 8$ & 168 & $55 \cdot 6$ & \\
\hline Yes & 74 & $23 \cdot 9$ & 125 & 28.6 & 98 & 32.4 & \\
\hline No answer & 43 & $13 \cdot 9$ & 64 & $14 \cdot 6$ & 36 & 11.9 & \\
\hline Clinical characteristics & & & & & & & \\
\hline $\mathrm{BMI}\left(\mathrm{kg} / \mathrm{m}^{2}\right)$ & 306 & & 430 & & 301 & & 0.13 \\
\hline Mean & & & & & & & \\
\hline SD & & & & & & & \\
\hline Total energy intake $(\mathrm{kJ} / \mathrm{d})$ & 310 & & 438 & & 302 & & 0.11 \\
\hline Mean & & & & & & & \\
\hline SD & & & & & & & \\
\hline Hypertension & 243 & 78.4 & 344 & 78.5 & 231 & $76 \cdot 5$ & 0.78 \\
\hline Hypercholesterolaemia & 174 & $56 \cdot 1$ & 241 & $55 \cdot 3$ & 184 & 60.9 & 0.28 \\
\hline Diabetes & 37 & $12 \cdot 0$ & 40 & $9 \cdot 3$ & 27 & $9 \cdot 0$ & 0.38 \\
\hline Smoking status & & & & & & & 0.08 \\
\hline Never & 189 & 61.0 & 268 & $61 \cdot 2$ & 209 & $69 \cdot 2$ & \\
\hline Ex-smoker & 104 & 33.6 & 147 & 33.6 & 86 & 28.5 & \\
\hline Current smoker & 17 & 5.5 & 23 & $5 \cdot 2$ & 7 & $2 \cdot 3$ & \\
\hline Plasma TAG (mmol/l) & 310 & & 434 & & 301 & & 0.82 \\
\hline Mean & & & & & & & \\
\hline SD & & & & & & & \\
\hline CVD & 17 & $5 \cdot 5$ & 27 & $6 \cdot 2$ & 16 & $5 \cdot 3$ & 0.88 \\
\hline Stroke & 9 & 2.9 & 11 & $2 \cdot 5$ & 9 & 3.0 & 0.91 \\
\hline apoE- $\varepsilon 4$ carrier & 53 & $17 \cdot 2$ & 81 & $18 \cdot 6$ & 60 & $20 \cdot 1$ & 0.65 \\
\hline
\end{tabular}

${ }^{*} P$ value for the $\chi^{2}$ test or ANOVA among categories of the MeDi score.

(Greece), spontaneous MeDi adherence was evaluated by a weighted MeDi score computed according to the frequency of consumption of eleven food groups (daily, weekly or monthly) ${ }^{(25)}$. In this small Greek sample, MeDi adherence was positively associated with plasma total $n-3$ PUFA, DHA, MUFA and MUFA:SFA ratio and inversely associated with plasma n-6 PUFA and the AA:EPA ratio in analyses adjusted for age, sex, physical activity and energy intake. However, traditionally distinct dietary habits in France and Greek could have induced discrepancies. Indeed, major characteristics of the Greek people are peculiar consumptions of vegetables and olive oil, whereas French people are greater consumers of alcohol, which would have influenced the country-specific MeDi adherence ${ }^{(3)}$. The association between a diet modelled on the traditional MeDi and blood fatty acid profile has already been investigated in several interventions studies which do not represent spontaneous dietary behaviours ${ }^{(31-34)}$. Most of these studies only involved men or women and were conducted on small samples. The largest study was the Lyon Heart Study (France) in which a modified Mediterraneantype diet was administered in a randomised secondary prevention trial in 605 patients recovering from myocardial infarction $^{(33)}$. In this study, the protective effect of the dietary intervention on CHD was related to changes in plasma fatty 
Table 3. Percentage of plasma fatty acids, fatty acid ratios and correlation analyses with Mediterranean diet (MeDi) adherence among older persons living in Bordeaux, the Three-City study (2001-2002) (Mean values, standard deviations and Pearson's coefficients, $n$ 1050)

\begin{tabular}{|c|c|c|c|c|}
\hline \multirow{2}{*}{$\begin{array}{l}\text { Fatty acids (\% of } \\
\text { total fatty acids) }\end{array}$} & \multirow[b]{2}{*}{ Mean } & \multirow[b]{2}{*}{ SD } & \multicolumn{2}{|c|}{ Correlation with the MeDi score $(0-9)$} \\
\hline & & & Pearson's coefficient $(\rho)$ & $P$ \\
\hline SFA & $41 \cdot 1$ & 8.6 & 0.023 & 0.45 \\
\hline $14: 0$ & $1 \cdot 3$ & 0.5 & -0.022 & 0.56 \\
\hline $16: 0$ & $28 \cdot 2$ & $5 \cdot 8$ & 0.017 & 0.31 \\
\hline $18: 0$ & 11.6 & 3.3 & 0.031 & 0.47 \\
\hline MUFA & $22 \cdot 6$ & 4.4 & -0.069 & 0.02 \\
\hline $16: 1 n-7$ & $2 \cdot 3$ & 0.9 & -0.097 & 0.002 \\
\hline $18: 1 n-9$ & $20 \cdot 3$ & 3.8 & -0.054 & 0.08 \\
\hline PUFA & $36 \cdot 3$ & $7 \cdot 0$ & 0.015 & 0.62 \\
\hline$n-6$ PUFA & $32 \cdot 0$ & 6.5 & -0.004 & 0.89 \\
\hline $18: 2 n-6$ & $24 \cdot 8$ & 5.4 & 0.007 & 0.81 \\
\hline $18: 3 n-6$ & 0.4 & 0.2 & -0.016 & 0.58 \\
\hline $20: 4 n-6$ & $6 \cdot 7$ & 1.8 & -0.034 & 0.27 \\
\hline$n-3$ PUFA & 4.3 & 1.4 & 0.096 & 0.002 \\
\hline $18: 3 n-3$ & 0.4 & 0.2 & -0.026 & 0.94 \\
\hline $20: 5 n-3$ & 1.0 & 0.6 & 0.048 & 0.11 \\
\hline $22: 5 n-3$ & 0.5 & 0.2 & 0.042 & 0.17 \\
\hline $22: 6 n-3$ & $2 \cdot 4$ & 0.8 & 0.117 & 0.0001 \\
\hline$E P A+D H A$ index & 3.4 & 1.3 & 0.099 & 0.001 \\
\hline \multicolumn{5}{|l|}{ Fatty acid ratios } \\
\hline MUFA:SFA & 0.6 & 0.1 & -0.042 & 0.17 \\
\hline$n-6: n-3$ PUFA & $8 \cdot 0$ & $2 \cdot 6$ & -0.093 & 0.002 \\
\hline LA:ALA & $70 \cdot 1$ & $32 \cdot 2$ & -0.032 & 0.30 \\
\hline AA:EPA & 8.3 & 4.7 & -0.081 & 0.008 \\
\hline $\mathrm{AA}: \mathrm{DHA}$ & $3 \cdot 0$ & 1.4 & -0.098 & 0.001 \\
\hline $\mathrm{AA}:(\mathrm{EPA}+\mathrm{DHA})$ & $2 \cdot 1$ & 0.8 & -0.108 & $<0.001$ \\
\hline
\end{tabular}

LA, linolenic acid; ALA, $\alpha$-linolenic acid; AA, arachidonic acid.

acids. Indeed, the intervention diet was associated with an increase in plasma $n-3$ PUFA and 18: $1 n-9$ and a decrease in 18:2n-6. However, the intervention group also benefited from a supplementation of $18: 3 n-3$ in addition to dietary recommendations. Other dietary indices close to the MeDi have been correlated with nutritional biomarkers. In a French population living near the Mediterranean basin, a Diet Quality Index (Med-DQI) has been developed and correlated with biological markers such as plasma carotene, vitamin $\mathrm{E}$ and the percentage of $20: 5 n-3$ and $22: 6 n-3$ in erythrocyte membrane ${ }^{(35)}$.

The relationship between plasma phospholipid fatty acids and dietary intakes of major food groups has been analysed in the European Prospective Investigation into Cancer and Nutrition study ${ }^{(36)}$. Strong correlations have been observed between fish intake and long-chain $n$-3 PUFA, on the one hand, and olive oil and 18:1n-9, on the other hand. Considering major food groups of the MeDi score, fish, which has only recently been added in the MeDi score computation ${ }^{(5)}$, is the main dietary source of long-chain $n$-3 PUFA. Previous reports have already shown a high correlation between fish intake and plasma $n-3$ PUFA $^{(37-41)}$. Fish consumption may in part explain the positive association between MeDi adherence and plasma long-chain n-3 PUFA, and the inverse association with several fatty acid ratios observed in the present study.

Consumption of alcohol, which is also a component of the MeDi score, might influence the metabolism of PUFA ${ }^{(42)}$ and has already been positively associated with plasma $20: 5 n-3$, 22:6n-3 and EPA + DHA index, even after controlling for fish consumption ${ }^{(36,43)}$. Alcohol was also positively associated with plasma $16: 0$ and $16: 1 n-7$ in Italian centres of the European Prospective Investigation into Cancer and Nutrition study $^{(44)}$. Since only a mild-to-moderate intake of alcohol is considered as a beneficial component of the MeDi score, the proportion of heavy drinkers decreased when the MeDi score increased. Hence, alcohol consumption could partly explain the observed association between higher MeDi adherence and lower plasma 16:1n-7. Another explanation is the decrease in the endogenous synthesis of $16: 1 n-7$ from SFA with increased MeDi adherence ${ }^{(45)}$.

The hallmark of the traditional MeDi is a very high consumption of olive oil leading to a high dietary MUFA:SFA ratio $^{(46)}$. However, in our sample, MeDi adherence was not associated with the plasma MUFA:SFA ratio or plasma SFA, and, surprisingly, inversely associated with plasma MUFA with borderline significance. These weaker associations with the MeDi score may be in part explained by the endogenous synthesis of these fatty acids, which may be a determinant compared with dietary contributions ${ }^{(41,45)}$. Moreover, total plasma lipids appear not to be good at reflecting small changes in MUFA ${ }^{(41)}$.

Few studies have analysed the interaction between dietary pattern or dietary fat and apoE genotype on lipid status and plasma fatty acids ${ }^{(47)}$. We found a positive association between MeDi adherence and plasma 20:5n-3 only among the apoE- $\varepsilon 4$ non-carriers. The plasma TAG-lowering effect of $20: 5 n-3$ and $22: 6 n-3$ is well known and may be in part mediated by apoE ${ }^{(48)}$. As already suggested, after $n$-3 PUFA 
Table 4. Percentage of plasma fatty acids and fatty acid ratios by categories of the Mediterranean diet (MeDi) score among older persons living in Bordeaux, the Three-City study (2001-2002)

(Mean values and standard deviations, $n$ 1050)

\begin{tabular}{|c|c|c|c|c|c|c|c|}
\hline \multirow[b]{2}{*}{ Total fatty acids (\%) } & \multicolumn{2}{|c|}{$\begin{array}{c}\text { Low category } \\
\text { (MeDi score 0-3) } \\
(n 310)\end{array}$} & \multicolumn{2}{|c|}{$\begin{array}{c}\text { Middle category } \\
\text { (MeDi score 4-5) } \\
\text { (n 438) }\end{array}$} & \multicolumn{2}{|c|}{$\begin{array}{c}\text { High category } \\
\text { (MeDi score 6-9) } \\
(n 302)\end{array}$} & \multirow[b]{2}{*}{$P^{*}$} \\
\hline & Mean & SD & Mean & SD & Mean & SD & \\
\hline SFA & $40 \cdot 6$ & $7 \cdot 6$ & $41 \cdot 2$ & 8.6 & $41 \cdot 3$ & $9 \cdot 4$ & 0.46 \\
\hline $14: 0$ & 1.2 & 0.4 & $1 . \overline{3}$ & 0.5 & $1 \cdot 2$ & 0.5 & 0.85 \\
\hline $16: 0$ & 27.9 & $5 \cdot 0$ & 28.4 & $6 \cdot 0$ & $28 \cdot 4$ & $6 \cdot 4$ & 0.53 \\
\hline $18: 0$ & 11.4 & $3 \cdot 2$ & 11.6 & 3.4 & $11 \cdot 7$ & 3.5 & 0.46 \\
\hline MUFA & 23.0 & 4.3 & 22.6 & 4.3 & $22 \cdot 3$ & 4.5 & 0.12 \\
\hline $16: 1 n-7$ & $2 \cdot 4$ & 1.0 & $2 \cdot 3$ & 0.9 & $2 \cdot 2 \dagger$ & 0.9 & $0.01 \ddagger$ \\
\hline $18: 1 n-9$ & $20 \cdot 6$ & $3 \cdot 7$ & $20 \cdot 2$ & 3.8 & $20 \cdot 1$ & $4 \cdot 0$ & 0.27 \\
\hline PUFA & $36 \cdot 4$ & $6 \cdot 6$ & $36 \cdot 2$ & $7 \cdot 0$ & $36 \cdot 3$ & $7 \cdot 4$ & 0.92 \\
\hline$n-6$ PUFA & $32 \cdot 3$ & $6 \cdot 2$ & 31.8 & $6 \cdot 4$ & $31 \cdot 8$ & 6.7 & 0.61 \\
\hline $18: 2 n-6$ & $25 \cdot 0$ & 5.3 & 24.7 & 5.5 & $24 \cdot 8$ & $5 \cdot 6$ & 0.77 \\
\hline $18: 3 n-6$ & 0.4 & 0.2 & 0.4 & 0.3 & 0.4 & 0.1 & 0.72 \\
\hline $20: 4 n-6$ & 6.9 & 1.9 & $6 \cdot 7$ & 1.8 & $6 \cdot 7$ & 1.9 & 0.44 \\
\hline$n-3$ PUFA & $4 \cdot 1$ & 1.2 & $4 \cdot 3$ & 1.4 & $4.5 \dagger$ & 1.5 & $0.004 \ddagger$ \\
\hline $18: 3 n-3$ & 0.4 & 0.2 & 0.4 & 0.2 & 0.4 & 0.1 & 0.99 \\
\hline $20: 5 n-3$ & 1.0 & 0.6 & 1.0 & 0.6 & $1 \cdot 1$ & 0.7 & 0.16 \\
\hline $22: 5 n-3$ & 0.4 & $0 \cdot 1$ & 0.5 & 0.2 & 0.5 & 0.1 & 0.28 \\
\hline $22: 6 n-3$ & $2 \cdot 3$ & 0.7 & $2 \cdot 4 \dagger$ & 0.8 & $2.5 \dagger$ & 0.9 & $0.0005 \ddagger$ \\
\hline$E P A+D H A$ index & 3.3 & $1 \cdot 1$ & 3.5 & 1.3 & $3.6+$ & 1.4 & $0.003 \ddagger$ \\
\hline \multicolumn{8}{|l|}{ Fatty acid ratios } \\
\hline MUFA:SFA & 0.6 & 0.1 & 0.6 & 0.1 & 0.6 & 0.2 & 0.23 \\
\hline$n-6: n-3$ PUFA & $8 \cdot 4$ & $2 \cdot 7$ & $7.9 \dagger$ & $2 \cdot 6$ & $7 \cdot 7 \dagger$ & $2 \cdot 4$ & $0.001 \ddagger$ \\
\hline LA:ALA & $71 \cdot 7$ & 34.5 & $70 \cdot 0$ & $32 \cdot 0$ & 68.5 & 30.0 & 0.45 \\
\hline$A A: E P A$ & 8.9 & $5 \cdot 1$ & $8 \cdot 2$ & 4.6 & $7.8 \dagger$ & 4.4 & $0.01 \ddagger$ \\
\hline AA:DHA & $3 \cdot 2$ & $1 \cdot 1$ & $3 \cdot 0$ & 1.8 & $2.8 \dagger$ & 1.0 & $0.007 \ddagger$ \\
\hline AA:(EPA + DHA) & $2 \cdot 3$ & 0.8 & $2 \cdot 1$ & 0.9 & $2.0 \dagger$ & 0.8 & $0.001 \ddagger$ \\
\hline
\end{tabular}

LA, linolenic acid; ALA, $\alpha$-linolenic acid; AA, arachidonic acid.

* $P$ value for the ANOVA among categories of the MeDi score.

† Mean values were significantly different for percentages of plasma fatty acids between categories of the MeDi score taking the lowest category as the reference group ( $2 \times 2$ significant comparisons): $P<0.05$

$\ddagger P$ values were significant after Bonferroni's correction.

supplementation, incorporation of EPA and DHA into plasma TAG is decreased by the presence of apoE- $\varepsilon 4^{(49)}$. Why only the association between plasma $20: 5 n-3$ and MeDi adherence was modified by apoE- $\varepsilon 4$ polymorphism is difficult to interpret, and further research is needed to better understand this gene $\times$ diet interaction.

The overall association between MeDi adherence and plasma $n$-3 PUFA seems to be of particular interest regarding their respective protective effect on cognitive decline and dementia in older people $\mathrm{e}^{(12,21,22)}$. In a previous analysis of the $3 \mathrm{C}$ study, we observed that higher MeDi adherence was significantly associated with better global cognitive performances over time ${ }^{(11)}$. We suggested that mechanisms by which the MeDi may exert its effect involved a decrease in oxidative stress, inflammation and vascular disease, which also participated in the pathophysiology of neurodegenerative disease ${ }^{(50-52)}$. Results from the present study reinforced these observations since mechanisms underlying the protective effect of long-chain $n-3$ PUFA on cognition could involve their anti-inflammatory or vascular properties in addition to their role in the composition and fluidity of neural membranes, and consequently in signal transduction and control of gene expression ${ }^{(21,22)}$.

The present results should be interpreted with caution because of some methodological limitations. First, the MeDi score only included nine food groups and, therefore, did not consider the overall correlation between foods ${ }^{(53)}$. The computation of the MeDi score based on sex-specific cut-off points does not measure adherence to a universal traditional MeDi pattern rather to a specific pattern, only characterising the study sample in which it was computed, which limits the generalisability of the present results ${ }^{(6)}$. Moreover, similar MeDi scores could reflect different dietary patterns, among the nine food groups considered for its computation. In the same way, the FFQ used in the present study assessed the number of servings of each food group but not portion size. Although our analyses were adjusted for total energy intake, we cannot exclude that the quantity of presumed protective or deleterious nutrients consumed by men and women with a similar MeDi score may differ. Second, dietary assessments were recorded slightly later than plasma measurements, and a single total plasma measurement was available. If subjects modified their dietary habits, this could have introduced variability in our analysis. A commonly held view suggests that erythrocyte fatty acid composition better reflects long-term dietary intake than plasma fatty acid levels ${ }^{(54,55)}$. Nevertheless, Hodson et al. ${ }^{(41)}$ demonstrated that, at best, erythrocytes and plasma lipid fractions both reflect only recent (few weeks) rather than long-term dietary fatty acid intakes. Previous analyses have reported that serum PUFA are suitable biomarkers 
Table 5. Association between plasma fatty acids and fatty acid ratios (separated models) and adherence to the Mediterranean diet (MeDi) in multivariate linear regression models among older persons living in Bordeaux, the Three-City study (2001-2002) ( $\beta$ Coefficients and $P$ values)

\begin{tabular}{|c|c|c|c|c|}
\hline \multirow[b]{2}{*}{ Total fatty acids (\%) } & \multicolumn{2}{|c|}{ Model $1^{\star}(n$ 1049) } & \multicolumn{2}{|c|}{ Model 2† (n 1026) } \\
\hline & $\beta$ & $P$ & $\beta$ & $P$ \\
\hline MUFA & -0.158 & 0.046 & -0.141 & 0.06 \\
\hline $16: 1 n-7$ & -0.052 & 0.003 & -0.049 & 0.003 \\
\hline $18: 1 n-9$ & -0.106 & 0.13 & -0.092 & 0.18 \\
\hline$n-3$ PUFA & 0.072 & 0.004 & 0.068 & 0.006 \\
\hline \multicolumn{5}{|l|}{$20: 5 n-3 \ddagger$} \\
\hline apoE- $\varepsilon 4$ carriers & -0.031 & 0.22 & -0.032 & 0.22 \\
\hline apoE- $\varepsilon 4$ non-carriers & 0.028 & 0.026 & 0.029 & 0.024 \\
\hline $22: 5 n-3$ & 0.003 & 0.25 & 0.004 & 0.16 \\
\hline $22: 6 n-3$ & 0.054 & 0.0003 & 0.051 & 0.0006 \\
\hline$E P A+D H A$ index & 0.069 & 0.002 & 0.066 & 0.004 \\
\hline \multicolumn{5}{|l|}{ Fatty acid ratios } \\
\hline MUFA:SFA & -0.003 & 0.22 & -0.003 & 0.24 \\
\hline$n-6: n-3$ PUFA & -0.134 & 0.004 & -0.140 & 0.002 \\
\hline AA:EPA & -0.216 & 0.012 & -0.215 & 0.013 \\
\hline AA:DHA & -0.078 & 0.002 & -0.075 & 0.0001 \\
\hline $\mathrm{AA}:(\mathrm{EPA}+\mathrm{DHA})$ & -0.051 & 0.0007 & -0.050 & 0.0005 \\
\hline
\end{tabular}

$\mathrm{AA}$, arachidonic acid.

* Adjusted for age, sex, energy intake and physical activity.

† Model 1 plus additional adjustment for smoking status, BMI, plasma TAG and apoE, allele $\varepsilon 4$ status.

$\mp$ Because of a significant interaction between the $\mathrm{MeDi}$ score and the apoE- $\varepsilon 4$ status $(P=0.03)$, analyses of the association between plasma EPA and the MeDi score were stratified according to the apoE- $\varepsilon 4$ status. Therefore, model 2 was not adjusted for apoE genotype.

of usual dietary intake over a few years, although the association may weaken as the delay between dietary assessment and blood collection increases ${ }^{(38)}$. Third, a selection bias cannot be dismissed and could have limited our ability to find additional or stronger associations. Indeed, plasma MUFA and 18:1n-9 were higher in not included subjects compared with those included, whereas plasma total $n$-3 PUFA and $20: 5 n-3$ were significantly higher in subjects enrolled in the present study compared with others. Finally, competition between metabolic pathways may lead to changes in fatty acid composition not directly related to the diet and may partly explain the present results ${ }^{(56)}$. Other unknown potential confounding factors related to both plasma fatty acids and MeDi adherence, such as other food groups not considered in the computation of the MeDi score or a general healthier lifestyle of MeDi adherents, could also partly explain the present results.

Despite these limitations, the strengths of the present study are its size, the population-based design and the control for numerous potential confounders. In particular, we controlled our analysis for BMI, energy intake, plasma TAG, physical activity and smoking status ${ }^{(57)}$. Smoking was associated with MeDi adherence with borderline significance in this sample and may affect PUFA status ${ }^{(41,58)}$. Moreover, physical activity, through its action on the energy turnover, modulates the metabolism of fatty acids independently of nutrition ${ }^{(59)}$. Adjustment for plasma TAG allowed us to control for the overall lipid status since plasma fatty acids are expressed as percentage of total fatty acids. Demented subjects were excluded to achieve a better reliability of information about nutritional intake.

To conclude, the present cross-sectional study shows that MeDi adherence was positively associated with plasma total $n$-3 PUFA and 22:6n-3 and inversely associated with plasma $16: 1 n-7$ and several $n-6: n-3$ PUFA ratios. Plasma 20:5n-3 was significantly positively associated with MeDi adherence only in apoE- $\varepsilon 4$ non-carriers, although this gene $\times$ diet interaction deserves further research ${ }^{(60)}$. These findings may explain the protective effect of the MeDi on cognitive functioning evidenced by two previous studies, although the generalisation of these results to other populations needs to be investigated.

\section{Acknowledgements}

The 3C study is conducted under a partnership agreement between the Institut National de la Santé et de la Recherche Médicale (INSERM), Victor Segalen - Bordeaux2 University and the Sanofi-Synthélabo company. The Fondation pour la Recherche Médicale funded the preparation and beginning of the study. The 3C study is also sponsored by the Caisse Nationale Maladie des Travailleurs Salariés, Direction Générale de la Santé, Conseils Régionaux of Aquitaine and Bourgogne, Fondation de France, Ministry of Research-INSERM Program 'Cohortes et collections de données biologiques'. Financial support for the 3C-COGINUT project was provided by the French National Research Agency (ANR-06-PNRA-005). C. F. was funded by the French National Research Agency (ANR06-PNRA-005). C. S. was funded by the Institut Carnot LISA (Lipides pour l'Industrie et la santé, Lipids for Industry, Safety and Health). Fatty acid analyses performed by E. P. were sponsored by the Conseil Régional d'Aquitaine. P. B.-G. received fees for conferences from Danone, Lesieur, Bauch\&Lomb and Aprifel, and benefits from research grants from Danone and Lesieur. None of the other authors had any financial or personal conflict of interest. The contribution of each author was as follows: P. B.-G. and A. P. S. designed and conducted the study. E. P. and P. B.-G. collected the data. P. B.-G. helped in the management of the data. C. F., M. J. M. T., M.-A. J., A. P. S. and P. B.-G. were responsible for the analysis and interpretation of the data. C. F. and P. B.-G. prepared the manuscript. C. F., M. J. M. T., C. S., M.-A. J., E. P., A. P. S. and P. B.-G. reviewed and approved the final version of the manuscript.

\section{References}

1. Keys A, Menotti A, Karvonen MJ, et al. (1986) The diet and 15-year death rate in the seven countries study. Am I Epidemiol 124, 903-915.

2. Simopoulos AP (2001) The Mediterranean diets: What is so special about the diet of Greece? The scientific evidence. J Nutr 131, Suppl. 11, 3065S-3073S.

3. Sofi F (2009) The Mediterranean diet revisited: evidence of its effectiveness grows. Curr Opin Cardiol 24, 442-446.

4. Willett WC, Sacks F, Trichopoulou A, et al. (1995) Mediterranean diet pyramid: a cultural model for healthy eating. Am J Clin Nutr 61, Suppl. 6, 1402S-1406S. 
5. Trichopoulou A, Costacou T, Bamia C, et al. (2003) Adherence to a Mediterranean diet and survival in a Greek population. N Engl J Med 348, 2599-2608.

6. Bach A, Serra-Majem L, Carrasco JL, et al. (2006) The use of indexes evaluating the adherence to the Mediterranean diet in epidemiological studies: a review. Public Health Nutr 9, $132-146$.

7. Sofi F, Cesari F, Abbate R, et al. (2008) Adherence to Mediterranean diet and health status: meta-analysis. BMJ 337, a1344.

8. Trichopoulou A, Bamia C \& Trichopoulos D (2009) Anatomy of health effects of Mediterranean diet: Greek EPIC prospective cohort study. BMJ 338, b2337.

9. Sofi F, Abbate R, Gensini GF, et al. (2010) Accruing evidence about benefits of adherence to the Mediterranean diet on health: an updated systematic review and meta-analysis. Am J Clin Nutr 92, 1189-1196.

10. Scarmeas N, Luchsinger JA, Schupf N, et al. (2009) Physical activity, diet, and risk of Alzheimer disease. JAMA 302, 627-637.

11. Feart C, Samieri C, Rondeau V, et al. (2009) Adherence to a Mediterranean diet, cognitive decline, and risk of dementia. JAMA 302, 638-648.

12. Feart C, Samieri C \& Barberger-Gateau P (2010) Mediterranean diet and cognitive function in older adults. Curr Opin Clin Nutr Metab Care 13, 14-18.

13. Reynolds E (2006) Vitamin $\mathrm{B}_{12}$, folic acid, and the nervous system. Lancet Neurol 5, 949-960.

14. Solfrizzi V, Colacicco AM, D'Introno A, et al. (2006) Dietary intake of unsaturated fatty acids and age-related cognitive decline: a 8.5-year follow-up of the Italian Longitudinal Study on Aging. Neurobiol Aging 27, 1694-1704.

15. Gomez-Pinilla F (2008) Brain foods: the effects of nutrients on brain function. Nat Rev Neurosci 9, 568-578.

16. Luchsinger JA \& Mayeux R (2004) Dietary factors and Alzheimer's disease. Lancet Neurol 3, 579-587.

17. Engelhart MJ, Geerlings MI, Ruitenberg A, et al. (2002) Dietary intake of antioxidants and risk of Alzheimer disease. JAMA 287, 3223-3229.

18. Letenneur L, Proust-Lima C, Le Gouge A, et al. (2007) Flavonoid intake and cognitive decline over a 10-year period. Am J Epidemiol 165, 1364-1371.

19. Berr C, Portet F, Carriere I, et al. (2009) Olive oil and cognition: results from the three-city study. Dement Geriatr Cogn Disord 28, 357-364.

20. Gillette Guyonnet S, Abellan Van Kan G, Andrieu S, et al. (2007) IANA task force on nutrition and cognitive decline with aging. J Nutr Health Aging 11, 132-152.

21. Cunnane SC, Plourde M, Pifferi F, et al. (2009) Fish, docosahexaenoic acid and Alzheimer's disease. Prog Lipid Res $\mathbf{4 8}$ 239-256.

22. Fotuhi M, Mohassel P \& Yaffe K (2009) Fish consumption, long-chain omega- 3 fatty acids and risk of cognitive decline or Alzheimer disease: a complex association. Nat Clin Pract Neurol 5, 140-152.

23. Yurko-Mauro K, McCarthy D, Rom D, et al. (2010) Beneficial effects of docosahexaenoic acid on cognition in age-related cognitive decline. Alzheimers Dement 6, 456-464.

24. Harris WS (2009) The omega-3 index: from biomarker to risk marker to risk factor. Curr Atheroscler Rep 11, 411-417.

25. Panagiotakos D, Kalogeropoulos N, Pitsavos C, et al. (2009) Validation of the MedDietScore via the determination of plasma fatty acids. Int J Food Sci Nutr 60, Suppl. 5, 168-180.

26. The 3C Study Group (2003) Vascular factors and risk of dementia: design of the Three-City Study and baseline characteristics of the study population. Neuroepidemiology 22, 316-325.
27. Peuchant E, Wolff R, Salles C, et al. (1989) One-step extraction of human erythrocyte lipids allowing rapid determination of fatty acid composition. Anal Biochem 181, 341-344.

28. Feart C, Jutand MA, Larrieu S, et al. (2007) Energy, macronutrient and fatty acid intake of French elderly community dwellers and association with socio-demographic characteristics: data from the Bordeaux sample of the Three-City Study. Br J Nutr 98, 1046-1057.

29. Samieri C, Jutand MA, Feart C, et al. (2008) Dietary patterns derived by hybrid clustering method in older people: association with cognition, mood, and self-rated health. J Am Diet Assoc 108, 1461-1471.

30. Dufouil C, Richard F, Fievet N, et al. (2005) APOE genotype, cholesterol level, lipid-lowering treatment, and dementia: the Three-City Study. Neurology 64, 1531-1538.

31. Djuric Z, Ren J, Blythe J, et al. (2009) A Mediterranean dietary intervention in healthy American women changes plasma carotenoids and fatty acids in distinct clusters. Nutr Res 29, 156-163.

32. Itsiopoulos C, Brazionis L, Kaimakamis M, et al. (2010) Can the Mediterranean diet lower HbA1c in type 2 diabetes? Results from a randomized cross-over study. Nutr Metab Cardiovasc Dis (Epublication ahead of print version 29 July 2010).

33. de Lorgeril M, Renaud S, Mamelle N, et al. (1994) Mediterranean alpha-linolenic acid-rich diet in secondary prevention of coronary heart disease. Lancet 343, 1454-1459.

34. Urquiaga I, Guasch V, Marshall G, et al. (2004) Effect of Mediterranean and Occidental diets, and red wine, on plasma fatty acids in humans. An intervention study. Biol Res 37, $253-261$

35. Gerber M (2006) Qualitative methods to evaluate Mediterranean diet in adults. Public Health Nutr 9, 147-151.

36. Saadatian-Elahi M, Slimani N, Chajes V, et al. (2009) Plasma phospholipid fatty acid profiles and their association with food intakes: results from a cross-sectional study within the European Prospective Investigation into Cancer and Nutrition. Am J Clin Nutr 89, 331-346.

37. Astorg P, Bertrais S, Laporte F, et al. (2008) Plasma n-6 and n3 polyunsaturated fatty acids as biomarkers of their dietary intakes: a cross-sectional study within a cohort of middleaged French men and women. Eur J Clin Nutr 62 , $1155-1161$.

38. Thiebaut AC, Rotival M, Gauthier E, et al. (2009) Correlation between serum phospholipid fatty acids and dietary intakes assessed a few years earlier. Nutr Cancer 61, 500-509.

39. Feart C, Peuchant E, Letenneur L, et al. (2008) Plasma eicosapentaenoic acid is inversely associated with severity of depressive symptomatology in the elderly: data from the Bordeaux sample of the Three-City Study. Am J Clin Nutr 87, 1156-1162.

40. Vandal M, Freemantle E, Tremblay-Mercier J, et al. (2008) Plasma omega-3 fatty acid response to a fish oil supplement in the healthy elderly. Lipids 43, 1085-1089.

41. Hodson L, Skeaff CM \& Fielding BA (2008) Fatty acid composition of adipose tissue and blood in humans and its use as a biomarker of dietary intake. Prog Lipid Res 47, 348-380.

42. Pawlosky RJ \& Salem N Jr (2004) Perspectives on alcohol consumption: liver polyunsaturated fatty acids and essential fatty acid metabolism. Alcohol 34, 27-33.

43. di Giuseppe R, de Lorgeril M, Salen P, et al. (2009) Alcohol consumption and $n-3$ polyunsaturated fatty acids in healthy men and women from 3 European populations. Am J Clin Nutr 89, 354-362. 
44. Fusconi E, Pala V, Riboli E, et al. (2003) Relationship between plasma fatty acid composition and diet over previous years in the Italian centers of the European Prospective Investigation into Cancer and Nutrition (EPIC). Tumori 89, 624-635.

45. Nakamura MT \& Nara TY (2004) Structure, function, and dietary regulation of delta6, delta5, and delta9 desaturases. Annu Rev Nutr 24, 345-376.

46. Panza F, Capurso C, D'Introno A, et al. (2007) Mediterranean diet, mild cognitive impairment, and Alzheimer's disease. Exp Gerontol 42, 6-7, author reply 8-9.

47. Anil E (2007) The impact of EPA and DHA on blood lipids and lipoprotein metabolism: influence of apoE genotype. Proc Nutr Soc 66, 60-68.

48. Balk EM, Lichtenstein AH, Chung M, et al. (2006) Effects of omega-3 fatty acids on serum markers of cardiovascular disease risk: a systematic review. Atherosclerosis 189, 19-30.

49. Plourde M, Vohl MC, Vandal M, et al. (2009) Plasma $n-3$ fatty acid response to an $n-3$ fatty acid supplement is modulated by apoE epsilon 4 but not by the common PPAR-alpha L162V polymorphism in men. Br J Nutr 102, 1121-1124.

50. Cummings JL (2004) Alzheimer's disease. N Engl J Med 351, 56-67.

51. Steele M, Stuchbury G \& Munch G (2007) The molecular basis of the prevention of Alzheimer's disease through healthy nutrition. Exp Gerontol 42, 28-36.

52. Razquin C, Martinez JA, Martinez-Gonzalez MA, et al. (2009) A 3 years follow-up of a Mediterranean diet rich in virgin olive oil is associated with high plasma antioxidant capacity and reduced body weight gain. Eur I Clin Nutr $\mathbf{6 3}$, $1387-1393$.

53. Jacques PF \& Tucker KL (2001) Are dietary patterns useful for understanding the role of diet in chronic disease? Am J Clin Nutr 73, 1-2.

54. Arab L (2003) Biomarkers of fat and fatty acid intake. J Nutr 133. Suppl. 3, 925S-932S.

55. Sun Q, Ma J, Campos H, et al. (2007) Comparison between plasma and erythrocyte fatty acid content as biomarkers of fatty acid intake in US women. Am J Clin Nutr 86, 74-81.

56. Simopoulos AP (2010) Genetic variants in the metabolism of omega- 6 and omega- 3 fatty acids: their role in the determination of nutritional requirements and chronic disease risk. Exp Biol Med (Maywood) 235, 785-795.

57. Hodge AM, Simpson JA, Gibson RA, et al. (2007) Plasma phospholipid fatty acid composition as a biomarker of habitual dietary fat intake in an ethnically diverse cohort. Nutr Metab Cardiovasc Dis 17, 415-426.

58. Pawlosky R, Hibbeln J, Wegher B, et al. (1999) The effects of cigarette smoking on the metabolism of essential fatty acids. Lipids 34, S287.

59. Nikolaidis MG \& Mougios V (2004) Effects of exercise on the fatty-acid composition of blood and tissue lipids. Sports Med 34, 1051-1076

60. Simopoulos AP (2007) Omega-3 fatty acids and athletics. Curr Sports Med Rep 6, 230-236. 